\title{
The relationship between cultural intelligence and bank performance: A case study of a private bank
}

\author{
Hassan Darvish $^{\mathrm{a}}$, Mina Khalili ${ }^{\mathrm{b}^{*}}$, and Majid Noodeh Farahani ${ }^{\mathrm{c}}$
}

\author{
${ }^{a}$ Assistant professor , Department of Economic ,Management and Accounting, Payame Noor University 19395-4697,Tehran, Iran \\ ${ }^{b}$ Graduate, Public Administration ‘Payame Noor University ,Tehran, Iran \\ ${ }^{c}$ Graduate, Public Administration ‘Payame Noor University ,Tehran, Iran
}

\section{H R O N I C L E}

Article history:

Received October 14, 2012

Received in revised format

24 December 2012

Accepted 5 January 2012

Available online

January 72013

Keywords:

Cultural intelligence

Banking industry

Performance measurement

\section{A B S T R A C T}

Cultural intelligence (CQ) is a new area of research, which is considered in different areas including banking industry. In this paper, we design a questionnaire in Likert scale and measure $\mathrm{CQ}$ in banking industry. The proposed study of this paper distributes 53 questionnaires among 60 employees of bank Sarmyeh, which is one of the private banks in Iran. The study also distributes a standard questionnaire among them to measure the performance of the same employees. Cronbach alpha are calculated for both questionnaires as 0.8155 and 0.9421 , respectively. The study calculates Pearson correlation ratio between these two items and the result indicates that there is a positive $(0.41)$ and meaningful relationship between $C Q$ and performance measurement. In addition, there is a positive and meaningful relationship between motivational CQ and performance measurement (0.378). However, the survey does not find any meaningful relationship between cognitive CQ, metacognitive CQ and behavioral CQ on one side and performance measurement.

\section{Introduction}

Nowadays, cultural intelligence (CQ) is believed to be one of the most influential factors in banking industry. There are different studies, which indicate there could be some relationships between cultural intelligence and performance of banking industry. There are different types of CQ such as cognitive, metacognitive and behavioral CQ and there are literally tremendous works associated with the relationships among these components. According to Balogh et al. (2012), cultural intelligence is one of the most influential competences in the 21st century. Balogh et al. (2012) investigated the CQ of fulltime university students in Hungary and the organizational culture of some companies. Although they found a correlation between the cultural intelligence of university students and the organizational culture of their future workplaces, they emphasized that the differences between the *Corresponding author.

E-mail addresses: minakhalili_88@yahoo.com (M.Khalili) 
actual organizational culture and the desired one pose great challenges for higher education. Goh (2012) discussed that globalization and multicultural characteristic of various countries and societies had placed an acute spotlight on whether nations were able to develop citizens who are multiculturally educated and globally engaged.

Crowne (2008) found some insight about the effect of cultural exposure on CQ, as well as developing of some insight on how the depth of cultural exposure impacts a person's CQ. The survey revealed that certain kinds of exposures to other cultures including education abroad and employment abroad and the level of exposure from these experiences could increase CQ. These findings were critical for multinational firms as managers hire, promote, train, and prepare workers for international assignments. Fischer (2011) investigated the use of a brief intercultural training intervention as part of a university course. They obtained measures of cultural essentialism and CQ were obtained before the first lecture and one week after the last training session ended. They demonstrated that cultural essentialism increased, but cognitive and meta-cognitive scores decreased following the intervention.

Shin-yih Chen et al. (2011) investigated the impact of CQ and its influence on performance of foreign laborers. They investigated the mediating impact of culture shock on the relationship between CQ and performance. They reported that CQ was positively associated with the performance of Philippine laborers and negatively associated with culture shock. They also reported that culture shock partly mediated the relationship of CQ and performance. They concluded that CQ could serve as a predictor for cross-cultural effectiveness and offered some implications for practice. Gelade (2008) investigated IQ, cultural values, and the technological achievement of nations and reported that technological progress could be enhanced where high-IQ individuals live in an intellectually open environment. Petrović (2011) determined the level of CQ of teachers and examined which variables were predictors of CQ. The study demonstrated that teachers showed a high level of CQ and that significant predictors of teachers' CQ were enjoyment of intercultural communication, experiencing multicultural classes as a challenge, openness to cultural learning and contacts with people from other cultures. Imai and Gelfand (2010) investigated the impact of CQ on negotiation sequences and outcomes and suggested that the level of integrative sequencing was more a function of the lowerscoring than the higher-scoring negotiator within the dyad. MacNab and Worthley (2012) investigated individual characteristics as predictors of cultural intelligence development by looking into the relevance of self-efficacy.

In this paper, we present an empirical investigation to study the effect of CQ on performance of a private bank in Iran. We first present details of our proposed model in section 2 and details of our finding are given in section 3 . The paper ends with concluding remarks to summarize the contribution of the paper.

\section{The proposed study}

The proposed study of this paper considers the impact of five different CQ on performance of banking sector. Fig. 1 demonstrates the framework of this study.

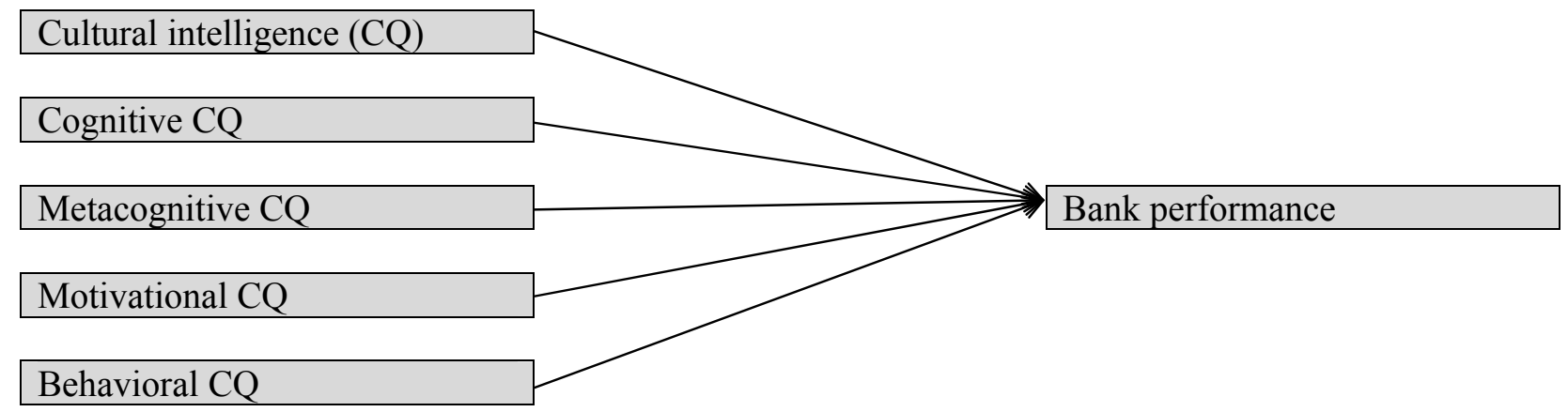

Fig. 1. Structure of the proposed study 
The proposed study of this paper is performed on one of the private Iranian banks called Sarmayeh with 60 managers and employees. We use the following formula to calculate the minimum number of sample size,

$n=\frac{N \times z_{\alpha / 2}^{2} \times p \times q}{\varepsilon^{2} \times(N-1)+z_{\alpha / 2}^{2} \times p \times q}$,

where $N$ is the population size, $p=1-q$ represents the yes/no categories, $z_{\alpha / 2}$ is CDF of normal distribution and finally $\varepsilon$ is the error term. Since we have $p=0.5, z_{\alpha / 2}=1.96$ and $N=60$, the number of sample size is calculated as $n=53$. The proposed study of this paper distributes 53 questionnaires among 60 employees of bank Sarmyeh, which is one of the private banks in Iran. The study also distributes a standard questionnaire among them to measure the performance of the same employees. Cronbach alpha (Cronbach, 1951) are calculated for both questionnaires as 0.8155 and 0.9421 , respectively. In our survey, $64.7 \%$ of the participants were male and the remaining $35.3 \%$ were female. In addition, $14 \%$ of the participants were manager and the remaining $86 \%$ were officers. In our survey, $25.5 \%$ of the participants only finished high school, $62.7 \%$ of them finished master degrees of science and $11.8 \%$ of the participants hold master degrees of science. Table 1 shows details of their job experiences.

Table 1

Details of job experiences of the participants

\begin{tabular}{lccccc}
\hline Job experience & Number & Maximum year & Minimum year & Mean & Standard deviation \\
\hline Regular & 50 & 1 & 37 & 11.25 & 10.32 \\
Management & 8 & 2 & 25 & 11 & 9.07 \\
\hline
\end{tabular}

In addition, Table 2 demonstrates some basic statistics including mean, standard deviation, etc. associated with five hypotheses of the survey.

Table 2

Basic statistics

\begin{tabular}{lcccccc}
\hline Variable & Number & Min & Max & Mean Likert & Standard deviation & Skewness \\
\hline Metacognitive CQ & 53 & 2.50 & 4.75 & 3.6274 & 0.4744 & 0.64 \\
Cognitive CQ & 53 & 1 & 3.83 & 2.6126 & 0.6085 & -0.667 \\
Motivational CQ & 53 & 1.20 & 4.60 & 3.4491 & 0.7557 & -1.026 \\
Behavioral CQ & 53 & 1.40 & 4.60 & 3.1066 & 0.7131 & -0.312 \\
Bank performance & 53 & 2.14 & 4.86 & 3.5782 & 0.5453 & -0.284 \\
\hline
\end{tabular}

\section{The results}

We now present details of our findings on testing five hypotheses of the survey using Pearson correlation test summarized in Table 3.

\section{Table 3}

The results of Pearson correlation test

\begin{tabular}{lcccl}
\hline Variable & Pearson correlation & P-Value & Number & Result \\
\hline Cultural CQ and bank performance & 0.412 & 0.012 & 36 & Confirmed \\
Metacognitive CQ and bank performance & 0.104 & 0.459 & 53 & Reject \\
Cognitive CQ and bank performance & 0.168 & 0.228 & 53 & Reject \\
Motivational CQ and bank Performance & 0.378 & 0.005 & - & Confirmed \\
Behavioral CQ and bank performance & 0.154 & 0.272 & - & Reject \\
\hline
\end{tabular}


As we can observe from the results of Table 3, there is a meaningful relationship between cultural CQ and bank performance when the level of significance is five percent. In addition, there is a meaningful relationship between motivational CQ and bank performance when the level of significance is either five or one percent. However, there are no meaningful relationships between Metacognitive CQ and bank performance, between Cognitive CQ and bank performance and between Behavioral CQ and bank performance. We have performed a regression analysis to find the effect of important variables on bank performance and in our survey indicated that only motivational CQ could actually have important impact on bank performance. In other words, motivational CQ could change $24 \%$ of the bank performance.

\section{Conclusion}

In this paper, we have performed an empirical investigation to find the effects of five CQ on the performance of banking industry. The proposed study of this paper designed two questionnaires and distributed among bank employees who worked for one of the private banks in Iran. The results of Pearson correlation test have indicated that only cultural and motivational CQ influenced bank performance and based on a regression analysis, we have concluded that motivational CQ could change $24 \%$ of the bank performance.

\section{References}

Balogh, A., Szabó, L., \& Gaál, Z. (2012). Cultural intelligence versus organizational culture: Relationship between hungarian students' cultural intelligence and the organizational culture of their prospective workplaces. International Journal of Diversity in Organisations, Communities and Nations, 11(1), 223-236.

Crowne, K.A. (2008). What leads to cultural intelligence? Business Horizons, 51(5), 391-399.

Cronbach, L. J. (1951). Coefficient alpha and the internal structure of tests. Psychometrika, 16(3), 297-334.

Fischer, R. (2011). Cross-cultural training effects on cultural essentialism beliefs and cultural intelligence. International Journal of Intercultural Relations, 35(6), 767-775.

Gelade, G.A. (2008). IQ, cultural values, and the technological achievement of nations. Intelligence, $36(6), 711-718$

Goh, M. (2012). Teaching with cultural intelligence: Developing multiculturally educated and globally engaged citizens. Asia Pacific Journal of Education, 32(4), 395-415.

Imai, L., Gelfand, M.J. (2010). The culturally intelligent negotiator: The impact of cultural intelligence (CQ) on negotiation sequences and outcomes. Organizational Behavior and Human Decision Processes, 112(2), 83-98.

MacNab, B.R., \& Worthley, R. (2012). Individual characteristics as predictors of cultural intelligence development: The relevance of self-efficacy. International Journal of Intercultural Relations, 36(1), 62-71.

Petrović, D.S. (2011).How do teachers perceive their cultural intelligence? Procedia - Social and Behavioral Sciences, 11, 276-280

Shin-yih Chen, A., Lin, Y.C., \& Sawangpattanakul, A. (2011). The relationship between cultural intelligence and performance with the mediating effect of culture shock: A case from Philippine laborers in Taiwan. International Journal of Intercultural Relations, 35(2), 246-258. 